\title{
DOENÇAS PÓS-COLHEITAEM VARIEDADES DE MANGA CULTIVADAS EM PINDORAMA, SÃO PAULO ${ }^{1}$
}

\author{
IVAN HERMAN FISCHER ${ }^{2}$, MARIA CECÍLIADE ARRUDA ${ }^{3}$, APARECIDA MARQUES DE ALMEIDA ${ }^{4}$, \\ JULIANAALTAFIN GALLI ${ }^{5}$, ROSEMARY MARQUES DE ALMEIDABERTANI ${ }^{6}$, \\ ELISANGELA MARQUES JERÔNIMO
}

RESUMO-O presente trabalho teve por objetivo avaliar a ocorrência de doenças pós-colheita em 15 variedades de manga, cultivadas em Pindorama-SP, sem adição de agroquímicos. Os frutos foram colhidos e submetidos a 24h de câmara úmida, permanecendo por mais nove dias a $25 \pm 2^{\circ} \mathrm{C}$ e $70-80 \%$ de UR. A incidência de podridões e a severidade da antracnose foram avaliadas em intervalos de três dias. No início do armazenamento, os frutos foram caracterizados quanto aos teores de sólidos solúveis e acidez titulável. A antracnose foi a doença mais frequente nas quinze variedades de manga, com $100 \%$ de incidência um dia após a colheita dos frutos, seguida pela podridão peduncular com média entre as variedades de 20,8\% ao final do armazenamento. Menor severidade de antracnose foi observada nas variedades Surpresa e Zill, enquanto menor incidência da podridão peduncular foi observada em 'Winter' e 'Pele-de-Moça'. Análises de correlação entre os parâmetros sólidos solúveis e acidez titulável das variedades com a intensidade da antracnose e da podridão peduncular foram significativas apenas entre acidez e antracnose, antes e após o período de armazenamento.

Termos para indexação: Mangifera indica, Colletotrichum, resistência.

\section{POSTHARVEST DISEASES OF MANGO VARIETIES CULTIVATED IN PINDORAMA, STATE OF SÃO PAULO}

\begin{abstract}
The present work aims to evaluate the occurrence of postharvest diseases of 15 mango varieties, cultivated in Pindorama, state of São Paulo, without chemical products. Fruits were individualized and kept in a humid chamber for $24 \mathrm{~h}$, previously at nine days period at $25 \pm 2^{\circ} \mathrm{C}$ and $70-80 \% \mathrm{RH}$. The incidence of postharvest diseases and the severity of anthracnose were evaluated in three days intervals. At the beginning of the storage period, the fruits were also characterized as to soluble solids and titratable acidity content. Anthracnose was the main disease in the fifteen varieties of mangos, with $100 \%$ of incidence one day after harvest, followed by stem-end rot, with average among the varieties of $20.8 \%$ at the end of the storage. Smaller anthracnose severity was observed in the Surpresa and Zill varieties, while smaller incidence of the stem-end rot was observed in Winter and Pele de Moça varieties. Correlation analyses among the soluble solid and titratable acidity parameters of the varieties with the intensity of the anthracnose and stem-end rot were just significant only between acidity and anthracnose, before and after the storage period.
\end{abstract}

Index Terms: Mangifera indica, Colletotrichum, resistance.

\footnotetext{
1' Trabalho 177-08). Recebido em: 02-07-2008. Aceito para publicação em: 02-04-2009.

${ }^{2}$ Dr. Pesquisador científico da APTA Centro Oeste Bauru, Av. Rodrigues Alves, 40-40, 17030-000, Bauru-SP, E-mail: ihfische@apta.sp.gov.br.

${ }^{3}$ Dra. Pesquisadora científica da APTA Centro Oeste Bauru, E-mail: mcarruda@apta.sp.gov.br.

${ }^{4}$ Dra. Pesquisadora científica da APTA Centro Oeste Bauru, E-mail: almeida@apta.sp.gov.br.

${ }^{5}$ Dra. Pesquisadora científica da APTA Centro Norte Pindorama-SP, E-mail: julianagalli@apta.sp.gov.br

${ }^{6}$ Dra. Pesquisadora científica da APTA Centro Oeste Bauru, E-mail: mjdemarchi@apta.sp.gov.br.

${ }^{7}$ Dra. Pesquisadora científica da APTA Centro Oeste Jaú-SP, E-mail: elijeronimo@apta.sp.gov.br.
} 


\section{INTRODUÇÃO}

A mangueira (Mangifera indica L.) é uma fruteira asiática que se adaptou muito bem ao clima brasileiro, produzindo inúmeras variedades e sendo facilmente encontrada desde a Amazônia até as regiões Sudeste e Centro-Oeste. As variedades que se destacam pela produção comercial são Haden, Keit, Palmer e Tommy Atkins (Sugai, 2002).

A vida pós-colheita da manga é limitada pelo desenvolvimento de patógenos, principalmente fungos que ocasionam podridões, e pelo amadurecimento e senescência natural da fruta, podendo as perdas alcançarem até $30 \%$ dos frutos (Silva et al., 2002). O reduzido tempo de vida útil após a colheita, em condições normais de temperatura ambiente, associado à colheita sazonal, condiciona a oferta e os preços no mercado. Além disso, a perda de água pelos frutos pode atingir níveis que causam seu enrugamento e murchamento que comprometem o aspecto visual e reduzem seu valor comercial (Pfaffenbach et al., 2003).

Dentre as várias doenças em pós-colheita da manga, a mais importante é a antracnose, causada por Colletotrichum gloeosporioides (Penz.) Penz. et Sacc., seguida pela podridão peduncular, causada por um complexo de fungos, sendo Lasiodiplodia theobromae (Pat.) Griffon \& Maubl. e Fusicoccum spp. os mais comuns em climas úmidos e quentes (Junqueira et al., 2002; Ploetz, 2003). A antracnose afeta todos os órgãos da planta, mas o prejuízo maior é causado nos frutos, onde aparecem manchas escuras irregulares na casca, que podem coalescer, envolvendo grandes áreas do fruto. A podridão peduncular caracteriza-se por uma podridão marromescura, com bordas bem definidas, começando pela região peduncular, local de penetração do patógeno (Cunha et al., 1993). Na maioria das vezes, o fruto já vem infectado do campo por estes patógenos, permanecendo quiescentes até que se estabeleçam condições propícias para o seu desenvolvimento, o que geralmente ocorre com o amadurecimento. Os prejuízos estão relacionados com a variedade, uma vez que o grau de resistência em relação à doença é variável (Maranca, 1980). A magnitude dos mecanismos de resistência, classificados em estruturais e bioquímicos, também varia em função da idade da planta, órgão/tecido afetados, estado nutricional e condições ambientais (Pascholati \& Leite, 1995). Outros patógenos secundários também podem causar podridões pós-colheita em manga, entre os quais, Alternaria alternata (Fr.:Fr) Keissl, Diaporthe citri Wolf, Aspergillus flavus Link, Pestalotia mangiferae Henn., Penicillium cyclopium Westling, Dothiorella spp. Phomopsis mangifera
Ahmad. e Rhizopus arrhizus Fischer (Ribeiro, 1997).

A crescente preocupação com o conceito de qualidade mercadológica e com a preservação do ambiente tem aumentado a procura por frutas saudáveis e sem resíduos de agroquímicos. Essa é, sem dúvida, uma tendência mundial irreversível e, nesse contexto, o uso de variedades resistentes, associado a outras técnicas de manejo integrado, é a medida mais eficaz, econômica e ecológica de controle de doenças e pragas.

A caracterização das doenças pós-colheita é necessária tanto para o estudo de medidas de controle, na caracterização da resistência varietal ou na determinação da eficiência de um fungicida, como para epidemiologia, na construção de curvas de progresso da doença e estimativa dos danos provocados por ela (Amorim, 1995). Diante disso, objetivou-se avaliar a resistência às doenças póscolheita de frutos de 15 variedades de manga, cultivadas sem o uso de agroquímicos, e correlacionar a ocorrência das doenças com o teor de sólidos solúveis e acidez titulável dos frutos.

\section{MATERIAL E MÉTODOS}

Foram caracterizados frutos de 15 variedades de manga (Tabela 1), previamente selecionadas (produtividade, uniformidade dos frutos e atributos sensoriais, como aroma e sabor) de uma coleção de 55 variedades, localizada no campo experimental da APTA Centro-Norte, município de Pindorama-SP (coordenadas 2113' S e 4856' W, com $562 \mathrm{~m}$ de altitude). A região apresenta um clima tropical, com verão quente e úmido e inverno ameno com estação seca acentuada, com amplitude média de temperatura de 16,6 a 30,5 ${ }^{\circ} \mathrm{C}$ e precipitação de $1.515 \mathrm{~mm}$, em 2007. O pomar estudado era composto por três plantas de cada variedade, enxertadas sobre a variedade Manila (Carabao), com idade superior a 10 anos, e espaçamento de 10 x 10 m. Nos últimos cinco anos, o pomar não foi adubado, assim como não recebeu aplicações de agroquímicos. O solo do campo experimental é caracterizado como Argissolo Vermelho-Amarelo eutrófico abrúptico, A moderado, textura arenosa/média (Oliveira et al., 1999). Análise química do solo do pomar revelou $\mathrm{pH}\left(\mathrm{CaCl}_{2}\right)=4,5$; $\mathrm{P}=13,0 \mathrm{mg} / \mathrm{dm}^{3} ; \mathrm{K}=4,3 \mathrm{mmol}_{\mathrm{c}} / \mathrm{dm}^{3} ; \mathrm{Ca}=12,0 \mathrm{mmol}_{\mathrm{c}}$ / $\mathrm{dm}^{3} ; \mathrm{Mg}=4,0 \mathrm{mmol} / \mathrm{dm}^{3} ; \mathrm{H}+\mathrm{Al}=28,0 \mathrm{mmol} / \mathrm{dm}^{3}, \mathrm{e}$ matéria orgânica $=11 \mathrm{~g} / \mathrm{dm}^{3}$. O controle das ervas daninhas foi feito por meio de roçadeira acoplada ao trator.

Para a caracterização das doenças póscolheita, foram realizadas duas colheitas de 25 frutos por variedade, coincidentemente, com os picos de 
colheita de cada variedade na região (Tabela 1 ). A colheita dos frutos foi realizada amostrando-se três plantas de cada variedade. Para a definição do ponto de colheita, utilizou-se como referência a aparência dos frutos, característica de cada variedade, em relação aos atributos formato, tamanho e coloração da casca, evitando-se os frutos imaturos e os excessivamente maduros.

Após a colheita, os frutos foram transportados para o laboratório da APTA - Bauru$\mathrm{SP}$, onde foram individualizados em bandejas plásticas e submetidos a 24 h de câmara úmida, visando a favorecer a ocorrência de podridões, permanecendo por mais nove dias a $25 \pm 2^{\circ} \mathrm{C}$ e 70 $80 \%$ de UR.

A incidência (número de frutos) de doenças pós-colheita e a severidade (área do fruto) da antracnose, principal doença diagnosticada, foram avaliadas visualmente após 1; 4; 7 e 10 dias da colheita dos frutos. Após a obtenção dos dados, calculou-se a área abaixo da curva de progresso da doença (AACPD), conforme Campbell \& Madden (1990). Os patógenos encontrados tiveram a patogenicidade confirmada mediante inoculação em frutos sadios, substituindo-se discos da casca por discos de micélio (5 mm de diâmetro). Os discos de micélio foram provenientes de colônias monospóricas cultivadas em meio BDA, durante sete dias (Moraes et al., 2006).

Doze frutos de cada amostra, em adição aos 25 frutos destinados à caracterização das doenças pós-colheita, foram destinados à determinação do teor de sólidos solúveis e acidez titulável (Nunes et al., 2008). Estas características físico-químicas foram correlacionadas com a incidência de doenças, e a severidade de antracnose, posteriormente analisadas pelo teste $\mathrm{F}(P<0,05)$.

Os resultados de incidência de doenças póscolheita e a severidade da antracnose, expressos como AACPD, assim como os teores de sólidos solúveis e a acidez titulável foram transformados em $(x+0,5)^{1 / 2}$, e as médias das variedades de manga, comparadas pelo teste de Tukey $(P<0,05)$.

\section{RESULTADOS E DISCUSSÃO}

As doenças pós-colheita encontradas nas 15 variedades de manga foram antracnose e podridão peduncular, sendo a incidência da antracnose, após um dia de armazenamento dos frutos, de $100 \%$ em todas as variedades. Houve diferença significativa entre as variedades em relação à severidade da antracnose, expressa por AACPD, no decorrer do armazenamento (Tabela 2 e
Figura 1A). As variedades Surpresa e Zill foram as mais resistentes, com 56,3 e 58,6 de AACPD no período de armazenamento, respectivamente, seguidas por Ubá, Rubi, Palmer, Rocha, Pele-de-Moça, Gouveia, Haden e Rosa; e as variedades Pope e Sensation, as mais suscetíveis, com 271,9 e 327,3 de AACPD, respectivamente (Tabela 2).

Quanto à reação à podridão peduncular, observou-se baixa incidência inicial, variando de 0$10 \%$ entre as variedades (Figura 1B). As variedades Winter e Pele-de-Moça foram as mais resistentes $(P<0,05)$, com 6 e 18 de AACPD, respectivamente, ao final do armazenamento, quando comparadas às variedades Rosa, Castro, Petacon e Pope, com AACPD superior a 120. As demais variedades apresentaram AACPD intermediária, sendo estatisticamente semelhantes (Tabela 2). Dentro do complexo de agentes patogênicos relatados como responsáveis pela podridão peduncular, foram identificados $L$. theobromae (46\%), Fusicoccum spp. (34\%) e Dothiorella spp. (18\%). A suscetibilidade da manga às podridões aumenta após a colheita e com o armazenamento, como resultado de mudanças fisiológicas nos frutos, favorecendo o desenvolvimento dos patógenos (Eckert at al., 1996).

Podridão decorrente do ataque de moscasdas-frutas foi observada em $2 \%$ dos frutos nas variedades Gouveia, Rubi e Surpresa; de 4\% na Pelede-Moça; 6\% na Sensation; 8\% na Petacon; 10\% na Castro e $36 \%$ na Pope. O restante das variedades não apresentou infestação por moscas-das-frutas. Outra podridão de menor importância, causada pelo patógeno fúngico Mucor hiemalis Wehm., foi observada nas variedades Castro e Pope, com $2 \%$ de incidência.

Em levantamento das doenças pós-colheita realizado em áreas irrigadas do submédio São Francisco do Nordeste brasileiro, Choudhury (1991) constatou cinco fungos patogênicos, em manga ‘Tommy Atkins', sendo C. gloeosporioides o mais importante, com uma frequência de 91,7\% nas amostras analisadas. Segundo Arauz (2000), em áreas de clima úmido, a incidência de antracnose nos frutos pode alcançar $100 \%$, semelhante ao constatado no presente trabalho. Na Costa Rica, a antracnose e a podridão peduncular foram as mais importantes doenças em pós-colheita de manga, com 85,7 e 10,4\% de incidência, respectivamente (Arauz \& Umana, 1986).

As 15 variedades de manga mostraram-se suscetíveis à antracnose e à podridão peduncular. Elevada suscetibilidade das variedades Haden e Sensation à antracnose já havia sido relatada por Maranca (1980), assim como menor suscetibilidade 
de Ubá e Palmer, por Silva et al. (2002). Informações sobre o comportamento às podridões das demais variedades analisadas são inexistentes ou pouco precisas. Mecanismos de resistência de mangas a patógenos podem estar relacionados a uma mistura de compostos antifúngicos presentes no fruto (Kobiler et al., 1998). A concentração do composto antifúngico resorcinol, presente na casca da manga, está diretamente relacionado à maior resistência de algumas variedades (Hassan et al., 2007), e decresce mais rapidamente, durante o amadurecimento, em variedades mais suscetíveis, como a Haden (Prusky \& Keen, 1993). Dentre os mecanismos de resistência da planta aos fitopatógenos, o resorcinol constitui apenas um dos compostos antifúngicos produzidos pela planta, existindo outros compostos e mecanismos, como as proteínas relacionadas à patogenicidade e as barreiras físicas, a exemplo da cutícula e da camada de cera, que também podem contribuir para a resistência (Hassan et al., 2007). Embora algumas variedades apresentem maior resistência, como é o caso da Tommy Atkins, nenhuma é suficientemente resistente para ser produzida sem o uso de fungicidas, em áreas úmidas (Dodd et al., 1997).

A ocorrência de temperatura e, principalmente, elevada umidade entre a floração e o desenvolvimento dos frutos, como ocorre na região Sudeste, é favorável à antracnose e à podridão peduncular (Manica et al., 2001; Zambolim \& Junqueira, 2004). A antracnose está amplamente disseminada em todas as regiões produtoras de manga no Brasil, embora não cause danos expressivos nas regiões de clima seco, o que tem motivado o plantio de pomares em regiões como as do semiárido nordestino (Cunha et al., 2000). Já o aumento da incidência da podridão peduncular em várias localidades, como as áreas irrigadas da região Nordeste, é motivo de grande preocupação (Cunha et al., 2000).

Os resultados confirmam a importância econômica das doenças pós-colheita em manga, visto que a simples presença dos sintomas desqualifica o fruto para comercialização, como destacado por Silva et al. (2002), que estimam perdas de até 30\%. A grande ocorrência de podridões sugere a necessidade de um manejo preventivo adequado, durante a florada e o desenvolvimento dos frutos, assim como um manejo em pós-colheita, visando a propiciar a redução dessas perdas (Dodd et al., 1997).

Nos pomares de mangas destinadas ao mercado externo, há necessidade de tratamentos fitossanitários pós-colheita, para que os frutos cheguem aos mercados importadores em boas condições de comercialização (Cunha et al., 1993), uma vez que, após a colheita, a disseminação dos patógenos pode ocorrer de fruto para fruto, em virtude da proximidade deles dentro das embalagens e as infecções quiescentes se desenvolverem (Ploetz, 2003). Dentre os métodos de controle de doenças em pós-colheita, o tratamento térmico é um dos mais empregados, combinado ou não com fungicida, durante cinco minutos.

Diversos fatores estão relacionados com a escolha da variedade de manga a ser plantada, dentre os quais o potencial produtivo da variedade para uma dada região, as limitações fitossanitárias e de pós-colheita e, principalmente, o potencial de mercado da variedade em médio prazo (CNPTIAEMBRAPA, 2004). O que leva o consumidor a selecionar a manga, é um fator baseado na aparência atraente do fruto preferencialmente avermelhado, polpa doce, contendo sólidos solúveis na faixa de 15 a 17\%, pouca ou nenhuma fibra, além de apresentar resistência ao manuseio (Leite et al, 1998). No presente trabalho, os teores de sólidos solúveis das variedades Sensation, Ubá, Winter, Pele-deMoça, Rubi, Pope e Petacon situaram-se entre 15,79 a $20,17^{\circ}$ Brix e foram maiores $(P<0,05)$ em relação às variedades Rocha e Surpresa, as quais apresentaram sólidos de 10,45 e 11,21 ${ }^{\circ}$ Brix, respectivamente (Tabela 3). Valores de acidez titulável também foram variáveis entre as variedades, com extremos entre 0,26 para Sensation e 1,14 para Surpresa (Tabela 3).

Análise de correlação entre os teores de sólidos solúveis e acidez titulável das variedades (Tabela 3) com a intensidade da antracnose e da podridão peduncular (Figura 1) foi significativa $(P<0,05)$ apenas entre acidez e a antracnose, antes (r $=-0,44)$ e após o período de armazenamento $(\mathrm{r}=$ $0,61)$. Associações entre o aumento das infecções com a elevação da concentração de sólidos solúveis ou a diminuição da acidez já foram relatadas em frutos de cereja (Northover \& Biggs, 1990), maçã (Sharma \& Kaul, 1988) e pêssego (Souza, 2007), podendo essas características auxiliar no entendimento das causas de resistência/suscetibilidade dos frutos de manga, assim como no planejamento da colheita. 
TABELA 1 - Variedades de manga e datas de colheita em Pindorama-SP.

\begin{tabular}{lcc}
\hline Variedades & \multicolumn{1}{c}{ Datas de colheita } \\
\hline Zill & $20-11-2007$ & O3-12-2008 \\
Surpresa & $20-11-2007$ & O3-12-2008 \\
Rocha & $20-11-2007$ & 03-12-2008 \\
Pele-de-Moça & $20-11-2007$ & 03-12-2008 \\
Gouveia & $20-11-2007$ & 03-12-2008 \\
Haden & $20-11-2007$ & O3-12-2008 \\
Rosa & $20-11-2007$ & $03-12-2008$ \\
Petacon & $03-12-2007$ & $19-12-2008$ \\
Rubi & $03-12-2007$ & $19-12-2008$ \\
Pope & $19-12-2007$ & $27-12-2008$ \\
Sensation & $19-12-2007$ & $27-12-2008$ \\
Ubá & $19-12-2007$ & $27-12-2008$ \\
Winter & $19-12-2007$ & $27-12-2008$ \\
Castro & $15-01-2008$ & $27-01-2008$ \\
Palmer & $15=01-2008$ & $27=01=2008$ \\
\hline
\end{tabular}

TABELA 2 - Área abaixo da curva de progresso da doença (AACPD) obtida a partir de quatro avaliações da incidência da podridão peduncular e da severidade da antracnose em variedades de manga* cultivadas sem agroquímicos, em Pindorama-SP.

\begin{tabular}{lcc}
\hline Variedades & AACPD- antracnose & AACPD- podridão peduncular \\
\hline Surpresa & $56,3 \mathrm{a}^{* *}$ & $51 \mathrm{ab}$ \\
Zill & $58,6 \mathrm{ab}$ & $96 \mathrm{ab}$ \\
Ubá & $72,5 \mathrm{abc}$ & $39 \mathrm{ab}$ \\
Rubi & $82,4 \mathrm{abc}$ & $90 \mathrm{ab}$ \\
Palmer & $86,8 \mathrm{abc}$ & $90 \mathrm{ab}$ \\
Rocha & $97,6 \mathrm{abc}$ & $93 \mathrm{ab}$ \\
Pele-de-Moça & $111,9 \mathrm{abcd}$ & $18 \mathrm{a}$ \\
Gouveia & $136,6 \mathrm{abcde}$ & $36 \mathrm{ab}$ \\
Haden & $163,2 \mathrm{abcde}$ & $42 \mathrm{ab}$ \\
Rosa & 195,4 bcde & $165 \mathrm{~b}$ \\
Castro & 205,9 cde & $132 \mathrm{~b}$ \\
Petacon & 216,9 cde & $129 \mathrm{~b}$ \\
Winter & 255,9 de & $6 \mathrm{a}$ \\
Pope & $271,9 \quad \mathrm{e}$ & $159 \mathrm{~b}$ \\
Sensation & $327,3 \quad \mathrm{e}$ & $78 \mathrm{ab}$ \\
\hline CV $(\%)$ & 22,7 & 38,6 \\
\hline
\end{tabular}

* Média de duas coletas de 25 frutos cada.** Dados seguidos pela mesma letra minúscula na coluna não diferem entre si, pelo teste de Tukey, ao nível de $5 \%$. O teste de Tukey foi aplicado sobre os dados transformados para $(\mathrm{x}+0,5)^{1 / 2}$.

TABELA 3 - Teores de acidez titulável e sólidos solúveis de variedades de manga* cultivadas sem agroquímicos, um dia após a colheita, em Pindorama-SP.

\begin{tabular}{lcc}
\hline Variedades & Acidez $(\%$ ácido cítrico) & Sólidos solúveis $\left({ }^{\circ}\right.$ Brix $)$ \\
\hline Sensation & $0,26 \mathrm{a}^{* *}$ & $15,92 \mathrm{bcd}$ \\
Ubá & $0,37 \mathrm{ab}$ & $20,17 \quad \mathrm{~d}$ \\
Winter & $0,38 \mathrm{ab}$ & $18,32 \mathrm{~cd}$ \\
Palmer & $0,39 \mathrm{abc}$ & $14,73 \mathrm{abc}$ \\
Pele-de-Moça & $0,46 \mathrm{abcd}$ & $15,87 \mathrm{bcd}$ \\
Castro & $0,48 \mathrm{abcd}$ & $13,96 \mathrm{abc}$ \\
Rubi & $0,51 \mathrm{abcd}$ & $16,17 \mathrm{bcd}$ \\
Pope & $0,55 \mathrm{bcd}$ & $15,79 \mathrm{bcd}$ \\
Petacon & $0,56 \mathrm{bcd}$ & $17,87 \mathrm{~cd}$ \\
Zill & $0,65 \mathrm{bcde}$ & $14,81 \mathrm{abc}$ \\
Rosa & $0,68 \mathrm{bcde}$ & $13,72 \mathrm{abc}$ \\
Haden & 0,73 cdef & $12,71 \mathrm{ab}$ \\
Gouveia & 0,83 def & $14,36 \mathrm{abc}$ \\
Rocha & 1,09 ef & $10,45 \mathrm{a}$ \\
Surpresa & $1,14 \quad \mathrm{f}$ & $11,21 \mathrm{a}$ \\
\hline CV $(\%)$ & $14,13 \quad$ & 7,93 \\
\hline
\end{tabular}

* Média de duas coletas de 12 frutos cada.** Dados seguidos pela mesma letra minúscula na coluna não diferem entre si, pelo teste de Tukey, ao nível de $5 \%$. O teste de Tukey foi aplicado sobre os dados transformados para $(x+0,5)^{1 / 2}$. 


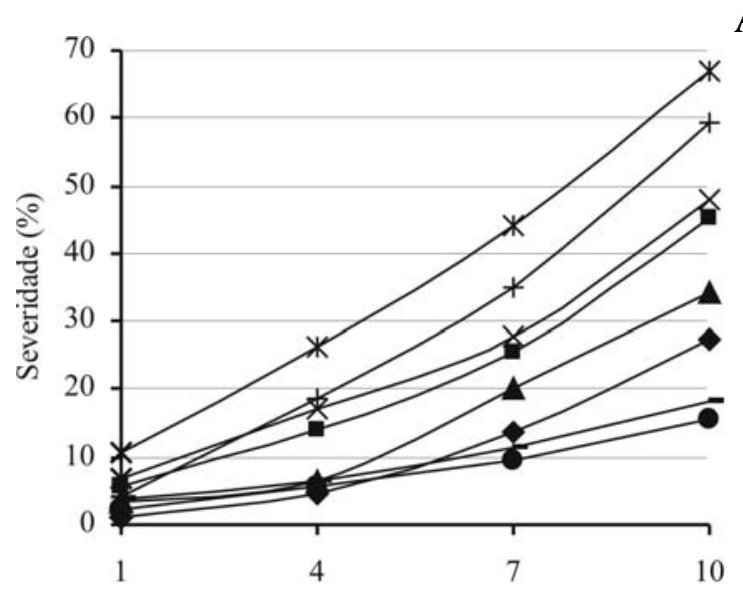

A

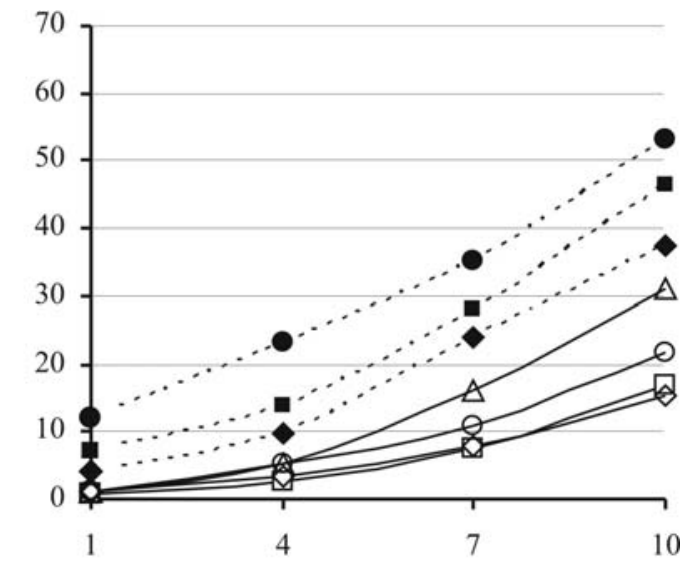

B
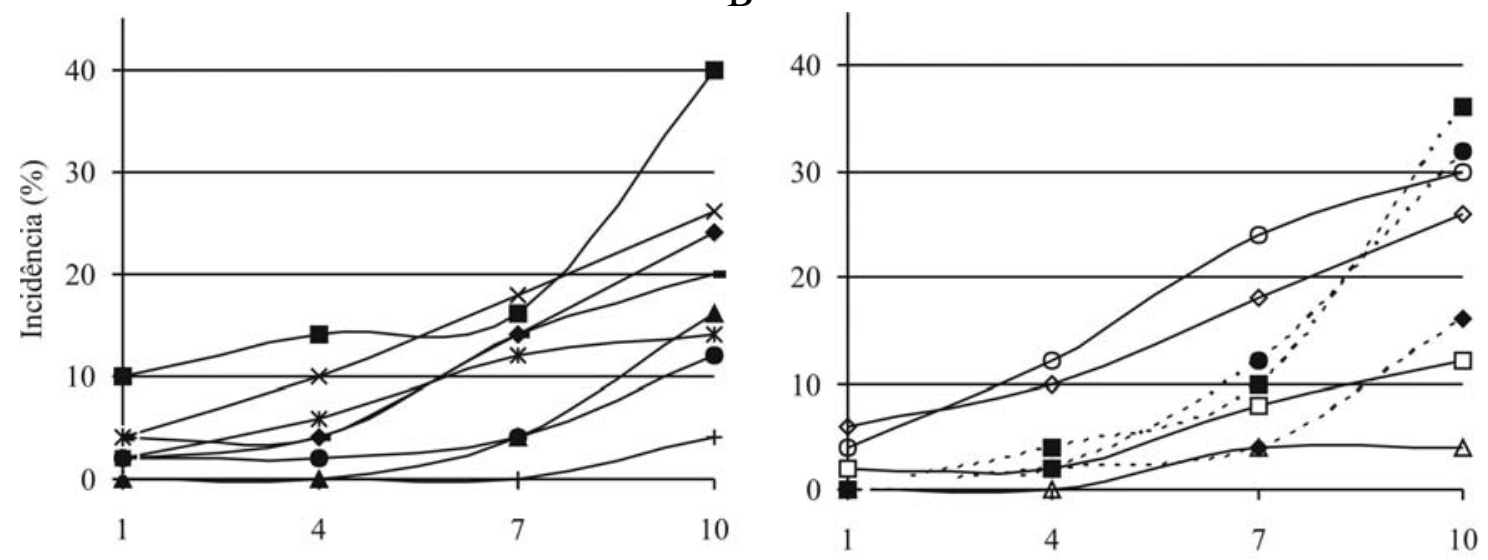

\begin{tabular}{|c|c|c|c|c|c|c|}
\hline$\multimap-$ Rocha & $\rightarrow-$ Rosa & Ł-Gouveia & $*$ Petacon & $\triangle$ Pele Moça ——— Surpresa & $\cdots \bullet$ Haden & $\longrightarrow$ Zill \\
\hline$\rightarrow$ - Sensarion & $\rightarrow$ Ubá & 工 Whinter & - Palmer & $\cdots \bullet \cdots$ Pope & …. Castro & \\
\hline
\end{tabular}

FIGURA 1 - Severidade da antracnose nos frutos (A) e incidência da podridão peduncular (B) em variedades de mangas cultivadas sem agroquímicos, em Pindorama-SP, durante dez dias de armazenamento a $25^{\circ} \mathrm{C}$.

\section{CONCLUSÕES}

1- A antracnose foi a doença pós-colheita mais frequente nas 15 variedades de manga cultivadas sem agroquímicos, seguida pela podridão peduncular.As variedades Surpresa e Zill foram as mais resistentes à antracnose, e as variedades Winter e Pele-de-Moça, à podridão peduncular.

2 - O teor de acidez titulável das mangas mostrou-se como uma das causas de resistência/ suscetibilidade à antracnose.

3 - A elevada ocorrência de doenças póscolheita nas variedades de manga reforça a necessidade de adoção de medidas preventivas e integradas no manejo fitossanitário da cultura, na região de Pindorama-SP.

\section{REFERÊNCIAS}

AMORIM, L. Avaliação de doenças. In: BERGAMIN, A.F.; KIMATI, H.; AMORIM, L. (Ed.). Manual de fitopatologia: princípios e conceitos. 3.ed. São Paulo: Agronômica Ceres, 1995. v.1. p.647-670.

ARAUZ, L.F. Mango anthracnose: economic impact and current options for integrated management. Plant Disease, Saint Paul, v.84, n.6, p.600-611, 2000.

ARAUZ, L.F.; UMANA, G. Diagnostico e incidência de las enfermidades poscosecha del mango em Costa Rica. Agronomia Costarricense, San José, v.10, p.89999, 1986. 
CAMPBELL, C.D.; MADDEN, L.V. Introduction to plant disease epidemiology. New York: John Willey, 1990. p.161-202.

CHOUDHURY, M. Doenças pós-colheita da manga produzida na região do submédio São Francisco durante o período chuvoso. Revista Brasileira de Fruticultura, Cruz das Almas, v.13, n.4, p.289-291, 1991.

CNPTIA-EMBRAPA. Sistemas de produção. 2004. Disponível em: <http:// sistemasdeproducao.cnptia.embrapa.br/ FontesHTML/Manga/CultivodaMangueira/ cultivares.htm>. Acesso em: 25 jun. 2008.

CUNHA, M.M.; SANTOS FILHO, H.P.; NASCIMENTO, A.S. Manga: fitossanidade. Brasília: Embrapa Comunicação para Transferência de Tecnologia, 2000. cap.3, p.25-47. (Frutas do Brasil, $6)$.

CUNHA, M.M.; COUTINHO, C.C.; JUNQUEIRA, N.T.V.; FERREIRA, F.R. Manga para exportação: aspectos fitossanitários. Brasília: MAARA-SDR; Embrapa-SPI, 1993. 104p. (FRUPEX. Publicações Técnicas, 3).

DODD, J.C.; PRUSKY, D.; JEFFRIES, P. Fruit diseases. In: LITZ, R.E. (Ed.) The mango: botany, production and uses. Oxon: CAB International, 1997. p.257-291.

ECKERT, J.W.; TARNAYAKE, M.; SIEVERT, J.R.; STRANGE, R.R. Curring citrus fruits to control postharvest diseases. In: CONGRESS OF THE INTERNATIONAL SOCIETY OF CITRICULTURE, 7., 1996, Sun City South Africa. Proceedings ... v.48, 1996.

HASSAN, M.K.; DANN, E.K.; IRVING, D.E.; COATES, L.M. Concentrations of constitutive alk(en)ylresorcinols in peel of commercial mango varieties and resistance to postharvest anthracnose. Physiological and Molecular Plant Pathology, Londres, v.71, n.4-6, p.158-165, 2007.

JUNQUEIRA, N.T.V.; PINTO, A.C. de Q.; CUNHA, M.M.; RAMOS, V.H.V. Controle das doenças da mangueira. In: ZAMBOLIM, M.L. (Ed.) Controle de doenças de plantas: fruteiras. Viçosa: UFV, 2002. v.1, p.323-404.
KOBILER, I.; REVED, R.; ARTEZ, L.; PRUSKY, D. Antifugal compounds regulating quiescent diseases in mango. ACIAR Proceedings Series, Canberra, v.80, n.1, p.109-114, 1998.

LEITE, L. A.S. O agronegócio da manga no Nordeste. In: CASTRO, A. M. G. (Ed.) Cadeias produtivas e sistemas naturais: prospecção tecnológica. Brasília: EMBRAPA- SPI, 1998. p.389-439.

MANICA, I.; ICUMA, I.M.; MALAVOLTA, E.; RAMOS, V.H.V.; OLIVEIRA JR, M.E.O.; CUNHA, M.M.; JUNQUEIRA, N.T.V. Tecnologia, produção, agroindústria e exportação de manga. Porto Alegre: Cinco Continentes, 2001. 617p.

MARANCA, G. Fruticultura comercial: manga e abacate. São Paulo: Nobel, 1980. 135p.

MORAES, W.S.; ZAMBOLIM, L.; LIMA, J.D. Incidência de fungos em pós-colheita de banana 'Prata-anã' (Musa AAB). Summa Phytopathologica, Botucatu, v.32, n.1, p.67-70, 2006.

NORTHOVER, J.; BIGGS, A.R. Susceptibility of immature and mature sweet and sour cherries to Monilinia fructicola. Plant Disease, Saint Paul, v.74, n.4, p.280-284, 1990.

NUNES, G.H.S.; BARROS, A.K.A.; QUEIRÓZ, M.A.; SILVA, R.A.; LIMA, L.L. Correlações entre características de meloeiro. Caatinga, Mossoró, v.21, n.1, p.107-112, 2008.

OLIVEIRA, J.B.; CAMARGO, M.N.; ROSSI, M.; CALDERANO FILHO, B. Mapa pedológico do Estado de São Paulo: legenda expandida. Campinas: IAC; Rio de Janeiro: EMBRAPA-Solos, 1999. 64p.

PASCHOLATI, S.F.; LEITE, B. Hospedeiro: mecanismos de resistência. In: BERGAMIN FILHO, A. (Ed.). Manual de fitopatologia: princípios e conceitos. 3.ed. São Paulo: Agronômica Ceres, 1995. v.1, cap.22, p.417- 453 .

PFAFFENBACH, L.B.; CASTRO, J.V. de; CARVALHO, C.L.; ROSSETO, C.J. Efeito da atmosfera modificada e da refrigeração na conservação pós-colheita de manga-espadavermelha. Revista Brasileira de Fruticultura, Jaboticabal, v.25, n.3, p.410-413. 2003. 
PLOETZ, RC. Diseases of mango. In: PLOETZ, R.C. (Ed.) Diseases of tropical fruit crops. Wallingford: CAB International, 2003. p.327-363.

PRUSKY, D.; KEEN, N.T. Involvement of preformed antifungal compounds in the resistance of subtropical fruits to fungal decay. Plant Disease, Saint Paul, v.77, n.1, 114-119, 1993.

RIBEIRO, I.J.A. Doenças da mangueira (Mangifera indica L.). In: KIMATI, H.; AMORIM, A.; BERGAMIN-FILHO, A.; CAMARGO, L.E.A.; REZENDE, J.A.M. Manual de fitopatologia: doenças das plantas cultivadas. São Paulo: Agronômica Ceres. 1997. v.2, p.511-524.

SHARMA, R.L.; KAUL, J.L. Susceptibility of apples to brown rot in relation to quantitative characters. Indian Phytopathology, New Delhi, v.43, p.113-115, 1988.

SILVA, C.R.R.; FONSECA, E.B.A.; MOREIRA, M.A. A cultura da mangueira. Lavras: UFLA, 2002. 116p.
SOUZA, D.C. Progresso temporal e padrão espacial de epidemias da podridão-parda-do-pessegueiro. 2007. 63f. Dissertação (Mestrado em Agronomia) Escola Superior de Agricultura Luiz de Queiroz, Universidade de São Paulo, Piracicaba, 2007.

SUGAI, Á.Y. Processamento descontínuo de purê de manga (Mangifera indica Linn.), variedade haden: estudo da viabilidade do produto para pronto consumo. 2002. 82 f. Dissertação (Mestrado em Engenharia) - Escola Politécnica da Universidade de São Paulo, São Paulo, 2002.

ZAMBOLIM, L.; JUNQUEIRA, N.T.V. Manejo Integrado de Doenças da Mangueira. In: ROZANE, D.E.; DAREZZO, R.J.; AGUIAR, R.L.; AGUILERA, G.H.A.; ZAMBOLIM, L. (Ed.). Manga: produção integrada, industrialização e comercialização. Viçosa: Universidade Federal de Viçosa, 2004. v.1, p.377-408. 